\title{
Integrated DNA methylation and gene expression analysis identified S100A8 and S100A9 in the pathogenesis of obesity
}

Ningyuan Chen ( $\nabla$ chenningyuan@gxmu.edu.cn )

Guangxi Medical University https://orcid.org/0000-0001-5004-6603

\section{Liu Miao}

Liu Zhou People's Hospital

Wei Lin

Jiangbin Hospital

Dong-Hua Zhou

Fifth Affiliated Hospital of Guangxi Medical University

\section{Ling Huang}

Guangxi Medical University

Jia Huang

Guangxi Medical University

\section{Wan-Xin Shi}

Guangxi Medical University

\section{Li-Lin Li}

Guangxi Medical University

\section{Yu-Xing Luo}

Guangxi Medical University

Hao Liang

Guangxi Medical University

\section{Shang-Ling Pan}

Guangxi Medical University

\section{Jun-Hua Peng}

Guangxi Medical University

\section{Research article}

Keywords: Obesity, DNA methylation-mRNA expression-CAD interaction network, Function enrichment, Correlation analyses

Posted Date: November 2nd, 2020 
DOl: https://doi.org/10.21203/rs.3.rs-68833/v2

License: (c) (1) This work is licensed under a Creative Commons Attribution 4.0 International License. Read Full License 


\section{Abstract}

Background: To explore the association of DNA methylation and gene expression in the pathology of obesity.

Methods: (1) Genomic DNA methylation and mRNA expression profile of visceral adipose tissue (VAT) were performed in a comprehensive database of gene expression in obese and normal subjects; (2) functional enrichment analysis and construction of differential methylation gene regulatory network were performed; (3) Validation of the two different methylation sites and corresponding gene expression was done in a separate microarray data set; and (4) correlation analysis was performed on DNA methylation and mRNA expression data.

Results: A total of 77 differentially expressed mRNA matched with differentially methylated genes. Analysis revealed two different methylation sites corresponding to two unique genes-s100a8cg09174555 and s100a9-cg03165378. Through the verification test of two interested different expression positions (DMPS) and their corresponding gene expression, we found that the methylation in these genes was negatively correlated to gene expression in the obesity group. Higher S100A8 and S100A9 expression in obese subjects were validated in a separate microarray data set.

Conclusion: This study confirmed the relationship between DNA methylation and gene expression and emphasized the important role of S100A8 and S100A9 in the pathogenesis of obesity.

\section{Introduction}

With the continuous improvement of living conditions, many countries have to pay more attention to the prevalence of obesity, because obesity has reached the proportion of epidemic that is still rising (Jensen et al. 2014). According to the World Health Organization's report in 2015, about one third or more adults are overweight, $43 \%$ of which is male and $45 \%$ as female (Collaborators et al. 2017). Obesity is implicated in many diseases, such as metabolic syndrome (MetS), type 2 diabetes (T2DM), hypertension, arteriosclerosis, cardiovascular disease (CVD), and so on (Global Burden of Metabolic Risk Factors for Chronic Diseases et al. 2014), and thus incur heavy economic burdens on countries around the world (Lozano et al. 2012). Obesity results from interactions between genetic and environmental factors, but for individuals, epigenetic factors can increase susceptibility to obesity (Sayols-Baixeras et al. 2017).

In recent years, with the deepening of research, epigenetics has emerged as a bridge between genes and environmental factors. It can change gene expression and induce long-term changes in phenotype and disease susceptibility (Smith et al. 2013). Extensive epigenomic association studies (EWAS) on DNA methylation conducted in many populations have revealed the relationship between DNA methylation and obesity (Xu et al. 2013). Changes in gene methylation changes can alter the transcription of genes resulting in abnormal gene expression and eventually obesity (Rodriguez-Rodero et al. 2017). 
Gene Expression Omnibus (GEO) database hosted the sequencing data of thousands of researchers, and its most important feature was that it provided open access to the data we needed to conduct our research. In the present study, we explored innovative methylation sites of obesity related DNA, by conducting an integration study using two microarray datasets, and established the relationship between the expression of obesity related genes and methylation (DEMGs). We then validated the DEMGs in a separate microarray dataset to explore the potential relationship between DNA methylation and mRNA expression on the regulation of obesity.

\section{Materials And Methods}

\section{Gene expression profile and probe labeling}

Three microarray datasets (GSE88837, GSE88940 and GSE109597) were downloaded from the gene expression database (https://www.ncbi.nlm.nih.gov/geo/) for analysis. GSE88837 was extracted from the U133 +2.0 sequence of gpl570 Affymetrix human genome for gene expression. In our study, subjects with $\mathrm{BMI} \geq 30$ were defined as obese (Jensen et al. 2014). A total of 30 subjects (including 15 obese and 15 healthy controls) were analyzed. We used the Affy package in R (Gautier et al. 2004) to convert the cel files into an expression value matrix and the RMA method to normalize the matrix. The Bioconductor package in R software was used to convert probe data into genes (Gentleman et al. 2004). If a gene corresponded to several probes, we choose the average expression value for further analysis. GSE88940 extracted from gpl13534, a human methylation 450 gene chip, was used for DNA methylation analysis, which consisted of 10 objects and 10 lean controls. All data processing was done in GEO2R (https://www.ncbi.nlm.nih.gov/geo/geo2r/). In these two data sets (GSE88837 and GSE88940), there are 20 samples of the same person. We only analyze these 20 samples. GSE109597 was used as the validation data set, and the analysis method was the same as used for GSE 88837.

\section{Differential expression and analysis of methylated genes (DEMGs)}

We compared obese with control subjects to explore the differential expression genes (DEGs) of the marginal envelope in $R$ (Miao et al. 2019). The threshold value was set as $\mid \log 2$ fold change $\mid \geq 2, P<$ 0.05. GEO2R was used to determine the methylation sites (DMPS) by comparing the differences between normal and obese subjects. DMPS located in gene regions were assigned to corresponding genes, which were defined as differentially methylated genes (DMGs). The threshold value was set as $\| \log _{2}$ foldchangel $(\Delta \beta)>0.05, P<0.05$. Then, we matched the DEGs with DMGs, and only the matched genes (DEMGs) were selected for further analysis.

\section{Functional enrichment analysis}

All functional enrichment analysis on DEGs was performed on cluster profiler and dose package in R (Yu et al. 2012). The complete functional enrichment analysis includes gene ontology (GO), Kyoto Encyclopedia of Genes and Genomes (KEGG) approach, and Disease Ontology (DO). The threshold value of analysis was set as adjust- $p<0.05$ and error detection rate $(F D R<0.05)$. 


\section{Protein-protein interaction (PPI) network and module analysis}

We used the string database (version 11.0) (Szklarczyk et al. 2019) to explore protein prediction and experimental interactions. There are many methods of database prediction, including co-expression experiment, text mining, co-occurrence, gene fusion, database, and neighborhood. , we used the combination fraction to reveal the protein pair interactions in the database. Then, we localized DEMGs to PPIs to identify the key genes in the network with the cut-off value set to a comprehensive score $>0.9$ (Miao et al. 2018). As a valuable method, a degree is used to study the role of protein nodes in the network. Using the molecular complex detection (MCODE) on Cytoscape (version 3.71), the most significant clustering module and the main clustering module were explored (Shannon et al. 2003; Bader et al. 2003). For further analysis, we set ease $\leq 0.05$ and set $\geq 2$ as the cutoff value and MCODE score > 8 as the threshold value.

\section{Validation of DEMGs}

We used prism 8.0 GraphPad (Miao et al. 2019) for scatterplots of methylation and gene expression to detect the relationship between methylation and gene expression. Then calculate the correlation equation to judge whether the equation has statistical significance. The DEMGs were validated in GSE109597, which contained 84 unrelated samples. After grouping according to BMI ( $>30$ and $<30$ ), the expression of DMEGs in the two groups was compared with ggplot2 in R.

\section{Result}

\section{Data preprocessing}

A quality control processing of GSE88837 showed that all samples were normal (Figure 1). We obtained 54560 expression probes from each gene map and expression. Probes with too low or too high probe expression were defined as outliers and eliminated from further analysis. An average expression value was used to screen the differentially expressed genes to prevent too many probes corresponding to one gene. The limma software package was used to calculate the DEGs, which yielded 1814 DEGs with $P$ values $<0.05$. We use the obese population as a reference, among these, 150 with a log2 (fold change) $>$ 2 were defined as up-regulated, and 199 with a log2 (fold change) $<2$ as down-regulated. The heat map and volcano map of DEGs are shown in Figure 2 ( $A$ and $B$ ).

Out of the 485579 DNA methylation sites in GSE88940 visceral adipose tissue (VAT) that were screened for quality control, 454325 methylation sites were selected for analysis. 10016 DMPS $(|\Delta \beta|>0.05, P<$ $0.05)$ were identified, of which 666 were hypermethylated and 3349 were hypomethylated. After annotation, 10016 DMPS are located in 4024 unique genes, which were identified as differentially methylated genes (DMGs). The thermal and volcanic maps of the DMGs are shown in Figure 2 (C and D).

Matching DMGs with DEGs yielded 77 genes for the next analysis (Figure 3). The details of 77 genes are shown in Table 1 and Figure 4. 
Table 1. The matched pairs of DEG and DMP 


\begin{tabular}{|c|c|c|c|c|c|c|c|c|c|}
\hline \multicolumn{8}{|c|}{ DMPs } & \multicolumn{2}{|c|}{ DEGs } \\
\hline SYMBOL & CpG site & START & END & $\mathrm{CHR}$ & Position & $\Delta \beta$ & $P$ values & FC & $P$ values \\
\hline ADH4 & $\operatorname{cg} 12011299$ & 100065546 & 100065669 & & TSS200 & $7.95 \mathrm{E}-02$ & $1.13 \mathrm{E}-02$ & -4.15 & $4.70 \mathrm{E}-03$ \\
\hline ASPHD1 & cg05192831 & 29913007 & 29913130 & 16 & 1stExon & $5.42 \mathrm{E}-02$ & $1.13 \mathrm{E}-02$ & -5.50 & $2.21 \mathrm{E}-02$ \\
\hline ASPHD1 & $\operatorname{cg} 02488299$ & 29913223 & 29913346 & 16 & 1stExon & $6.23 \mathrm{E}-02$ & $1.13 \mathrm{E}-02$ & -5.50 & $2.21 \mathrm{E}-02$ \\
\hline BNC1 & $\operatorname{cg} 27169020$ & 83954229 & 83954352 & 15 & TSS1500 & $7.85 \mathrm{E}-02$ & $1.13 \mathrm{E}-02$ & -2.54 & $3.92 \mathrm{E}-02$ \\
\hline BNC1 & $\operatorname{cg} 23741520$ & 83954231 & 83954354 & 15 & TSS1500 & 7.86E-02 & $1.13 \mathrm{E}-02$ & -2.54 & $3.92 \mathrm{E}-02$ \\
\hline BNC1 & $\operatorname{cg} 12250049$ & 83951663 & 83951786 & 15 & Body & $8.56 \mathrm{E}-02$ & $1.13 \mathrm{E}-02$ & -2.54 & $3.92 \mathrm{E}-02$ \\
\hline BNC1 & $\operatorname{cg} 10275315$ & 83954246 & 83954369 & 15 & TSS1500 & $9.20 \mathrm{E}-02$ & $1.13 \mathrm{E}-02$ & -2.54 & $3.92 \mathrm{E}-02$ \\
\hline BNC1 & $\operatorname{cg} 00768409$ & 83954392 & 83954515 & 15 & TSS1500 & $9.23 \mathrm{E}-02$ & $1.13 \mathrm{E}-02$ & -2.54 & $3.92 \mathrm{E}-02$ \\
\hline BNC1 & cg16049391 & 83954395 & 83954518 & 15 & TSS1500 & $1.06 \mathrm{E}-01$ & $1.13 \mathrm{E}-02$ & -2.54 & $3.92 \mathrm{E}-02$ \\
\hline C1orf87 & $\operatorname{cg} 17238766$ & 60539675 & 60539798 & 1 & TSS1500 & $8.87 \mathrm{E}-02$ & $1.13 \mathrm{E}-02$ & 3.84 & $1.19 \mathrm{E}-02$ \\
\hline C1orf87 & $\operatorname{cg} 09851465$ & 60539671 & 60539794 & 1 & TSS1500 & $1.07 \mathrm{E}-01$ & $1.13 \mathrm{E}-02$ & 3.84 & $1.19 \mathrm{E}-02$ \\
\hline C3orf22 & $\operatorname{cg} 07743179$ & 126278943 & 126279066 & 3 & TSS1500 & $-5.14 \mathrm{E}-02$ & $1.13 \mathrm{E}-02$ & 2.63 & $4.95 \mathrm{E}-02$ \\
\hline $\mathrm{CFB}$ & $\operatorname{cg} 12124018$ & 31916683 & 31916806 & 6 & Body & $-6.73 E-02$ & $1.13 \mathrm{E}-02$ & -3.60 & $1.23 \mathrm{E}-04$ \\
\hline $\mathrm{CFB}$ & $\operatorname{cg} 21606287$ & 31916705 & 31916828 & 6 & Body & $-6.17 E-02$ & $1.13 \mathrm{E}-02$ & -3.60 & $1.23 \mathrm{E}-04$ \\
\hline CGN & $\operatorname{cg} 07596668$ & 151509825 & 151509948 & 1 & 3'UTR & $8.20 \mathrm{E}-02$ & $1.13 \mathrm{E}-02$ & -4.83 & $1.38 \mathrm{E}-02$ \\
\hline CGN & $\operatorname{cg} 25198049$ & 151509723 & 151509846 & 1 & Body & $8.29 \mathrm{E}-02$ & $1.13 \mathrm{E}-02$ & -4.83 & $1.38 \mathrm{E}-02$ \\
\hline CHI3L1 & $\operatorname{cg} 14085262$ & 203155938 & 203156061 & 1 & TSS200 & $5.79 \mathrm{E}-02$ & $1.13 \mathrm{E}-02$ & -3.09 & $1.38 \mathrm{E}-02$ \\
\hline CRB2 & $\operatorname{cg} 15922174$ & 126135998 & 126136121 & 9 & Body & $-8.61 \mathrm{E}-02$ & $1.13 \mathrm{E}-02$ & -4.69 & $3.40 \mathrm{E}-03$ \\
\hline CRB2 & cg02625222 & 126135169 & 126135292 & 9 & Body & $5.30 \mathrm{E}-02$ & $1.13 \mathrm{E}-02$ & -4.69 & $3.40 \mathrm{E}-03$ \\
\hline CRB2 & $\operatorname{cg} 11431402$ & 126135408 & 126135531 & 9 & Body & $5.76 \mathrm{E}-02$ & $1.13 \mathrm{E}-02$ & -4.69 & $3.40 \mathrm{E}-03$ \\
\hline CRB2 & $\operatorname{cg} 13884995$ & 126126377 & 126126500 & 9 & Body & $7.19 \mathrm{E}-02$ & $1.13 \mathrm{E}-02$ & -4.69 & $3.40 \mathrm{E}-03$ \\
\hline DMRTA1 & $\operatorname{cg} 14338345$ & 22447679 & 22447802 & 9 & 1stExon & $5.36 \mathrm{E}-02$ & $1.13 \mathrm{E}-02$ & 4.92 & $1.79 \mathrm{E}-02$ \\
\hline DUSP1 & $\operatorname{cg} 08452061$ & 172199642 & 172199765 & 5 & TSS1500 & $5.88 \mathrm{E}-02$ & $1.13 \mathrm{E}-02$ & 5.41 & $6.80 \mathrm{E}-03$ \\
\hline EPHA1 & $\operatorname{cg} 21294616$ & 143093848 & 143093971 & 7 & Body & $-6.88 \mathrm{E}-02$ & $1.13 \mathrm{E}-02$ & 3.61 & $3.53 \mathrm{E}-02$ \\
\hline EPHA1 & $\operatorname{cg} 26960083$ & 143106298 & 143106421 & 7 & TSS1500 & $6.90 \mathrm{E}-02$ & $1.13 \mathrm{E}-02$ & 3.61 & 3.53E-02 \\
\hline ESPN & $\operatorname{cg} 13284574$ & 6519923 & 6520046 & 1 & Body & 7.33E-02 & $1.13 \mathrm{E}-02$ & 4.19 & $2.59 \mathrm{E}-02$ \\
\hline FAM84A & $\operatorname{cg} 12050497$ & 14773274 & 14773397 & 2 & 5'UTR & $9.44 \mathrm{E}-02$ & $1.13 \mathrm{E}-02$ & -4.84 & $9.04 \mathrm{E}-03$ \\
\hline FGF9 & $\operatorname{cg} 03688324$ & 22251017 & 22251140 & 13 & Body & $6.28 \mathrm{E}-02$ & $1.13 \mathrm{E}-02$ & -2.68 & $1.25 \mathrm{E}-02$ \\
\hline FNDC1 & cg06764804 & 159654028 & 159654151 & 6 & Body & $5.46 \mathrm{E}-02$ & $1.13 \mathrm{E}-02$ & -3.50 & $1.97 \mathrm{E}-02$ \\
\hline GPR143 & cg19318920 & 9693690 & 9693813 & $\mathrm{X}$ & 3'UTR & $5.73 \mathrm{E}-02$ & $1.13 \mathrm{E}-02$ & -2.33 & $3.60 \mathrm{E}-02$ \\
\hline GPRIN3 & $\operatorname{cg} 02734358$ & 90227074 & 90227197 & 4 & 5 'UTR & $1.06 \mathrm{E}-01$ & $1.13 \mathrm{E}-02$ & -4.03 & $2.18 \mathrm{E}-02$ \\
\hline GSC & $\operatorname{cg} 01695643$ & 95237330 & 95237453 & 14 & TSS1500 & $8.16 \mathrm{E}-02$ & $1.13 \mathrm{E}-02$ & 2.62 & $3.78 \mathrm{E}-02$ \\
\hline GSC & $\operatorname{cg} 15440688$ & 95237637 & 95237760 & 14 & TSS1500 & $9.33 \mathrm{E}-02$ & $1.13 \mathrm{E}-02$ & 2.62 & $3.78 \mathrm{E}-02$ \\
\hline ITGA2B & $\operatorname{cg} 14686645$ & 42452426 & 42452549 & 17 & Body & $6.75 \mathrm{E}-02$ & $1.13 \mathrm{E}-02$ & 2.59 & $1.34 \mathrm{E}-02$ \\
\hline KCNK3 & $\operatorname{cg} 19115882$ & 26919145 & 26919268 & 2 & Body & $5.71 \mathrm{E}-02$ & $2.04 \mathrm{E}-03$ & -2.31 & $4.83 \mathrm{E}-03$ \\
\hline KCNK3 & $\operatorname{cg} 19991086$ & 26953767 & 26953890 & 2 & 3'UTR & $6.04 \mathrm{E}-02$ & $2.04 \mathrm{E}-03$ & -2.31 & $4.83 \mathrm{E}-03$ \\
\hline KCNN3 & $\operatorname{cg} 16296829$ & 154832535 & 154832658 & 2 & TSS200 & $6.21 \mathrm{E}-02$ & $2.04 \mathrm{E}-03$ & -2.31 & $4.83 \mathrm{E}-03$ \\
\hline KCNN3 & $\operatorname{cg} 18315680$ & 154833117 & 154833240 & 2 & Body & 8.39E-02 & $2.04 \mathrm{E}-03$ & -2.31 & $4.83 \mathrm{E}-03$ \\
\hline KLF2 & cg02668248 & 16437789 & 16437912 & 19 & Body & $-7.35 \mathrm{E}-02$ & $2.04 \mathrm{E}-03$ & 3.95 & $1.90 \mathrm{E}-02$ \\
\hline KLHL34 & cg20312916 & 21676605 & 21676728 & $\mathrm{x}$ & TSS200 & $-6.58 \mathrm{E}-02$ & $2.04 \mathrm{E}-03$ & 3.99 & $1.49 \mathrm{E}-02$ \\
\hline KLHL34 & $\operatorname{cg} 01828474$ & 21676593 & 21676716 & $\mathrm{x}$ & TSS200 & $-5.27 \mathrm{E}-02$ & $2.04 \mathrm{E}-03$ & 3.99 & $1.49 \mathrm{E}-02$ \\
\hline KLHL34 & $\operatorname{cg} 25075572$ & 21673930 & 21674053 & $\mathrm{X}$ & 1stExon & $-5.05 \mathrm{E}-02$ & $2.04 \mathrm{E}-03$ & 3.99 & $1.49 \mathrm{E}-02$ \\
\hline KRT7 & $\operatorname{cg} 25313172$ & 52627272 & 52627395 & 12 & 1stExon & $-6.67 \mathrm{E}-02$ & $2.04 \mathrm{E}-03$ & -3.94 & $2.60 \mathrm{E}-02$ \\
\hline KRT7 & $\operatorname{cg} 14537533$ & 52626904 & 52627027 & 12 & TSS200 & $-6.14 \mathrm{E}-02$ & $2.04 \mathrm{E}-03$ & -3.94 & $2.60 \mathrm{E}-02$ \\
\hline KRT7 & $\operatorname{cg} 07967679$ & 52626814 & 52626937 & 12 & TSS200 & $-5.58 \mathrm{E}-02$ & $2.04 \mathrm{E}-03$ & -3.94 & $2.60 \mathrm{E}-02$ \\
\hline KRT7 & $\operatorname{cg} 07022048$ & 52638592 & 52638715 & 12 & Body & $6.70 \mathrm{E}-02$ & $2.04 \mathrm{E}-03$ & -3.94 & $2.60 \mathrm{E}-02$ \\
\hline KRT71 & $\operatorname{cg} 23767977$ & 52947465 & 52947588 & 15 & TSS1500 & $5.19 \mathrm{E}-02$ & $2.04 \mathrm{E}-03$ & 3.47 & $3.17 \mathrm{E}-02$ \\
\hline KRT8 & $\operatorname{cg} 24504361$ & 53297987 & 53298110 & 12 & Body & $6.83 \mathrm{E}-02$ & $2.04 \mathrm{E}-03$ & -2.20 & $4.88 \mathrm{E}-03$ \\
\hline LAD1 & $\operatorname{cg} 11418783$ & 201369650 & 201369773 & 1 & TSS1500 & $5.47 \mathrm{E}-02$ & $2.04 \mathrm{E}-03$ & 2.97 & $1.95 \mathrm{E}-02$ \\
\hline MARCO & $\operatorname{cg} 07554474$ & 119698443 & 119698566 & 2 & TSS1500 & $6.99 \mathrm{E}-02$ & $2.04 \mathrm{E}-03$ & -2.45 & $1.73 \mathrm{E}-02$ \\
\hline $\mathrm{MC} 2 \mathrm{R}$ & $\operatorname{cg} 25924472$ & 13884152 & 13884275 & 18 & 3'UTR & $-1.15 \mathrm{E}-01$ & $2.04 \mathrm{E}-03$ & 4.96 & $3.62 \mathrm{E}-03$ \\
\hline MFAP4 & cg15119221 & 19290755 & 19290878 & 17 & TSS1500 & $6.26 \mathrm{E}-02$ & $2.04 \mathrm{E}-03$ & 2.22 & $3.19 \mathrm{E}-02$ \\
\hline MYT1L & $\operatorname{cg} 14128411$ & 1926907 & 1927030 & 2 & Body & $-1.08 \mathrm{E}-01$ & $2.04 \mathrm{E}-03$ & -2.32 & $4.16 \mathrm{E}-02$ \\
\hline MYT1L & $\operatorname{cg} 00067742$ & 1926888 & 1927011 & 2 & Body & $-7.81 \mathrm{E}-02$ & $2.04 \mathrm{E}-03$ & -2.32 & $4.16 \mathrm{E}-02$ \\
\hline MYT1L & $\operatorname{cg} 09022325$ & 1796228 & 1796351 & 2 & Body & $5.95 \mathrm{E}-02$ & $2.04 \mathrm{E}-03$ & -2.32 & $4.16 \mathrm{E}-02$ \\
\hline
\end{tabular}




\begin{tabular}{|c|c|c|c|c|c|c|c|c|c|}
\hline MYT1L & $\operatorname{cg} 22388316$ & 2000192 & 2000315 & 2 & 5 'UTR & 8.38E-02 & $2.04 \mathrm{E}-03$ & -2.32 & 4.16E-02 \\
\hline NGFR & $\operatorname{cg} 04466214$ & 47581280 & 47581403 & 17 & Body & $5.49 \mathrm{E}-02$ & $2.04 \mathrm{E}-03$ & -2.34 & $4.35 \mathrm{E}-03$ \\
\hline NGFR & $\operatorname{cg} 17369032$ & 47590326 & 47590449 & 17 & Body & 7.93E-02 & $2.04 \mathrm{E}-03$ & -2.34 & $4.35 \mathrm{E}-03$ \\
\hline PCDHB3 & $\operatorname{cg} 01925738$ & 140480770 & 140480893 & 5 & 1stExon & $-7.09 \mathrm{E}-02$ & $2.04 \mathrm{E}-03$ & 3.59 & $1.00 \mathrm{E}-02$ \\
\hline PKD2L2 & $\operatorname{cg} 10535132$ & 137224284 & 137224407 & 5 & TSS1500 & $6.68 \mathrm{E}-02$ & $2.04 \mathrm{E}-03$ & -3.16 & $2.52 \mathrm{E}-02$ \\
\hline ROR2 & $\operatorname{cg} 14244439$ & 94561075 & 94561198 & 9 & Body & $5.75 \mathrm{E}-02$ & $2.04 \mathrm{E}-03$ & -2.71 & $2.79 \mathrm{E}-02$ \\
\hline ROR2 & $\operatorname{cg} 02785332$ & 94647670 & 94647793 & 9 & Body & $6.55 \mathrm{E}-02$ & $2.04 \mathrm{E}-03$ & -2.71 & $2.79 \mathrm{E}-02$ \\
\hline RXFP1 & cg03875996 & 159442782 & 159442905 & 4 & TSS1500 & $7.56 \mathrm{E}-02$ & $2.04 \mathrm{E}-03$ & 4.77 & $6.47 \mathrm{E}-03$ \\
\hline S100A8 & $\operatorname{cg} 09174555$ & 153364020 & 153364143 & 1 & TSS1500 & 7.03E-02 & $2.04 \mathrm{E}-03$ & -2.25 & $8.00 \mathrm{E}-03$ \\
\hline S100A9 & $\operatorname{cg} 03165378$ & 153329882 & 153330005 & 1 & TSS1500 & $7.51 \mathrm{E}-02$ & $2.04 \mathrm{E}-03$ & -2.05 & $1.13 \mathrm{E}-02$ \\
\hline SCTR & cg26009192 & 120282200 & 120282323 & 2 & TSS200 & $-5.88 \mathrm{E}-02$ & $2.04 \mathrm{E}-03$ & 2.45 & $4.12 \mathrm{E}-02$ \\
\hline SGPP2 & $\operatorname{cg} 14435109$ & 223288714 & 223288837 & 2 & TSS1500 & $5.72 \mathrm{E}-02$ & $2.04 \mathrm{E}-03$ & -3.25 & $2.72 \mathrm{E}-03$ \\
\hline SGPP2 & $\operatorname{cg} 07873848$ & 223288635 & 223288758 & 2 & TSS1500 & $6.25 \mathrm{E}-02$ & $2.04 \mathrm{E}-03$ & -3.25 & $2.72 \mathrm{E}-03$ \\
\hline SGPP2 & $\operatorname{cg} 11300809$ & 223288637 & 223288760 & 2 & TSS1500 & 7.03E-02 & $2.04 \mathrm{E}-03$ & -3.25 & $2.72 \mathrm{E}-03$ \\
\hline SGPP2 & $\operatorname{cg} 10091265$ & 223288331 & 223288454 & 2 & TSS1500 & 7.16E-02 & $2.04 \mathrm{E}-03$ & -3.25 & $2.72 \mathrm{E}-03$ \\
\hline SGPP2 & $\operatorname{cg} 16171484$ & 223290515 & 223290638 & 2 & Body & 7.99E-02 & $2.04 \mathrm{E}-03$ & -3.25 & $2.72 \mathrm{E}-03$ \\
\hline SMPD3 & $\operatorname{cg} 07735969$ & 68418473 & 68418596 & 16 & 5 'UTR & $6.49 \mathrm{E}-02$ & $2.04 \mathrm{E}-03$ & -3.52 & 2.63E-02 \\
\hline SRGN & $\operatorname{cg} 18278184$ & 70847430 & 70847553 & 10 & TSS1500 & 8.69E-02 & $2.04 \mathrm{E}-03$ & 3.49 & 4.83E-02 \\
\hline TNRC18 & $\operatorname{cg} 06947694$ & 5389271 & 5389394 & 7 & Body & $-7.03 \mathrm{E}-02$ & $2.04 \mathrm{E}-03$ & -2.58 & $1.12 \mathrm{E}-02$ \\
\hline TNRC18 & cg19679210 & 5354874 & 5354997 & 7 & Body & $6.58 \mathrm{E}-02$ & $2.04 \mathrm{E}-03$ & -2.58 & $1.12 \mathrm{E}-02$ \\
\hline TNXB & & 32077744 & 32077867 & 6 & & $-8.95 \mathrm{E}-02$ & & 2.82 & $2.92 \mathrm{E}-02$ \\
\hline TNXB & $\operatorname{cg} 13199127$ & 32049196 & 32049319 & 6 & Body & $-8.53 \mathrm{E}-02$ & $2.04 \mathrm{E}-03$ & 2.82 & $2 \mathrm{E}-02$ \\
\hline TNXB & & 32026610 & 32026733 & 6 & Body & $-7.77 \mathrm{E}-02$ & $2.04 \mathrm{E}-03$ & 2.82 & $2.92 \mathrm{E}-02$ \\
\hline TNXB & $\operatorname{cg} 00661399$ & 32049177 & 32049300 & 6 & Body & $-7.60 \mathrm{E}-02$ & $2.04 \mathrm{E}-03$ & 2.82 & $2.92 \mathrm{E}-02$ \\
\hline TNXB & $\operatorname{cg} 24336152$ & 32070785 & 32070908 & 6 & 5 'UTR & $-7.03 E-02$ & $2.04 \mathrm{E}-03$ & 2.82 & $2.92 \mathrm{E}-02$ \\
\hline TNXB & $\operatorname{cg} 14669361$ & 32038747 & 038870 & 6 & , & $91 \mathrm{E}-02$ & 00589 & 2.82 & 92E-02 \\
\hline TNXB & $\operatorname{cg} 20858622$ & 32015651 & 32015774 & 6 & Body & $-6.80 \mathrm{E}-02$ & $9.84 \mathrm{E}-03$ & 2.82 & $2.92 \mathrm{E}-02$ \\
\hline TNXB & $\operatorname{cg} 11493661$ & 32016239 & 32016362 & 6 & Body & $-6.70 \mathrm{E}-02$ & $5.63 \mathrm{E}-03$ & 2.82 & $2.92 \mathrm{E}-02$ \\
\hline TNXB & $\operatorname{cg} 05956076$ & 32074934 & 32075057 & 6 & 5'UTR & $-6.55 \mathrm{E}-02$ & $2.97 \mathrm{E}-02$ & 2.82 & $2.92 \mathrm{E}-02$ \\
\hline TNXB & $\operatorname{cg} 16478197$ & 32068181 & 32068304 & 6 & 5'UTR & $-6.32 \mathrm{E}-02$ & $2.04 \mathrm{E}-03$ & 2.82 & $2.92 \mathrm{E}-02$ \\
\hline TNXB & $\operatorname{cg} 12493058$ & 32052444 & 32052567 & 6 & Body & $5.59 \mathrm{E}-02$ & $1.69 \mathrm{E}-02$ & 2.82 & $2.92 \mathrm{E}-02$ \\
\hline TNXB & cg20928974 & 32022642 & 32022765 & 6 & Body & $5.68 \mathrm{E}-02$ & $1.97 \mathrm{E}-02$ & 2.82 & $2.92 \mathrm{E}-02$ \\
\hline TNXB & $\operatorname{cg} 16662408$ & 32053637 & 32053760 & 6 & Body & 5.95E-02 & $2.36 \mathrm{E}-02$ & 2.82 & $2.92 \mathrm{E}-02$ \\
\hline TNXB & $\operatorname{cg} 23636802$ & 32054441 & 32054564 & 6 & Body & 7.13E-02 & $2.36 \mathrm{E}-02$ & 2.82 & $2.92 \mathrm{E}-02$ \\
\hline TNXB & $\operatorname{cg} 13606255$ & 32053100 & 32053223 & 6 & Body & $7.94 \mathrm{E}-02$ & $2.36 \mathrm{E}-02$ & 2.82 & $2.92 \mathrm{E}-02$ \\
\hline TNXB & $\operatorname{cg} 13739666$ & 32013974 & 32014097 & 6 & TSS200 & $-7.87 \mathrm{E}-02$ & $2.36 \mathrm{E}-02$ & 2.82 & $2.92 \mathrm{E}-02$ \\
\hline TNXB & $\operatorname{cg} 26537323$ & 32014059 & 32014182 & 6 & TSS200 & $-7.60 \mathrm{E}-02$ & $2.36 \mathrm{E}-02$ & 2.82 & $2.92 \mathrm{E}-02$ \\
\hline TNXB & $\operatorname{cg} 18178844$ & 32014100 & 32014223 & 6 & TSS200 & $-6.24 \mathrm{E}-02$ & $2.36 \mathrm{E}-02$ & 2.82 & $2.92 \mathrm{E}-02$ \\
\hline TNXB & $\operatorname{cg} 25522795$ & 32014096 & 32014219 & 6 & TSS200 & $-5.09 \mathrm{E}-02$ & $2.36 \mathrm{E}-02$ & 2.82 & $2.92 \mathrm{E}-02$ \\
\hline TNXB & cg15376677 & 32011687 & 32011810 & 6 & Body & $5.40 \mathrm{E}-02$ & $2.36 \mathrm{E}-02$ & 2.82 & $2.92 \mathrm{E}-02$ \\
\hline TNXB & cg18340416 & 32010178 & 32010301 & 6 & Body & $5.89 \mathrm{E}-02$ & $2.36 \mathrm{E}-02$ & 2.82 & $2.92 \mathrm{E}-02$ \\
\hline TNXB & cg20161227 & 31980836 & 31980959 & 6 & 5'UTR & $-7.46 \mathrm{E}-02$ & $2.36 \mathrm{E}-02$ & 2.82 & $2.92 \mathrm{E}-02$ \\
\hline TRIML1 & $\operatorname{cg} 04086012$ & 189060900 & 189061023 & 4 & 1stExon & $5.25 \mathrm{E}-02$ & $2.36 \mathrm{E}-02$ & -3.35 & $2.19 \mathrm{E}-02$ \\
\hline $\mathrm{UNC} 13 \mathrm{C}$ & $\operatorname{cg} 06530558$ & 54304778 & 54304901 & 15 & TSS1500 & $5.72 \mathrm{E}-02$ & $2.36 \mathrm{E}-02$ & 2.07 & $4.67 \mathrm{E}-02$ \\
\hline VWA5B1 & cg 05805297 & 20617329 & 20617452 & 1 & TSS200 & $7.04 \mathrm{E}-02$ & $2.36 \mathrm{E}-02$ & 4.25 & $1.29 \mathrm{E}-02$ \\
\hline VWA5B1 & $\operatorname{cg} 04637372$ & 20617456 & 20617579 & 1 & 5'UTR & $7.54 \mathrm{E}-02$ & $2.36 \mathrm{E}-02$ & 4.25 & $1.29 \mathrm{E}-02$ \\
\hline VWA5B1 & $\operatorname{cg} 25745746$ & 20617452 & 20617575 & 1 & 5 'UTR & 8.04E-02 & $2.36 \mathrm{E}-02$ & 4.25 & $1.29 \mathrm{E}-02$ \\
\hline WNK4 & $\operatorname{cg} 06795963$ & 40932359 & 40932482 & 17 & TSS1500 & $-7.78 \mathrm{E}-02$ & $2.36 \mathrm{E}-02$ & -3.68 & $1.54 \mathrm{E}-02$ \\
\hline ZDHHC1 & $\operatorname{cg} 06139166$ & 67440283 & 67440406 & 16 & Body & $-1.02 \mathrm{E}-01$ & $2.36 \mathrm{E}-02$ & 2.14 & $1.65 \mathrm{E}-02$ \\
\hline ZDHHC1 & $\operatorname{cg} 08968184$ & 67433636 & 67433759 & 16 & Body & $5.10 \mathrm{E}-02$ & $2.36 \mathrm{E}-02$ & 2.14 & $1.65 \mathrm{E}-02$ \\
\hline ZFR2 & cg09999510 & 3812479 & 3812602 & 19 & Body & $5.01 \mathrm{E}-02$ & $2.36 \mathrm{E}-02$ & 2.71 & $3.06 \mathrm{E}-02$ \\
\hline
\end{tabular}

CHR, chromosome; DEG, differentially expressed gene; $\Delta \beta$, difference of methylation between patients with Obesity and healthy controls; DMP, differential methylation position; START/END, position in Build 37; FC, log fold change 


\section{Functional annotation}

The cluster profiler package in R for DO function, KEGG pathway enrichment, and GO analysis was used to clarify the role of the DEGs. 104 cell components, 7 molecular functions, and 329 biological processes were significantly enriched in GO (corrected $\mathrm{P}<0.05$, Figure 5A and Supplementary Table 1). Also, 22 pathways were enriched in KEGG, and $77 \mathrm{DO}$ items were identified at $\mathrm{p}<0.05$ after correction (error detection rate, FDR $<0.05$ ). The results are shown in Figure 5 ( $B$ and $C$ ) and Supplementary Tables 2 and 3.

Enrichments including GO: 0061448 connective tissue development, GO: 0007584 nutritional response, GO: 0022600 digestive system process, GO: 0045444 adipocyte differentiation, hsa04010 MAPK signal pathway, hsa04657 IL-17 signal pathway, hsa0061 fatty acid biosynthesis, hsa04933 age-old signal pathway in diabetic complications, DOID: 9352 Type 2 diabetes mellitus; DOID: 374 nutritional diseases; DOID: 654 over nutrition; DOID: 9970 obesity have been previously reported to be related to obesity, and thus genes in these clusters were selected for further analysis.

\section{Construction of PPI network and identification of key genes}

The string database was used to clarify gene interaction networks of the selected genes on Cytoscape, which revealed 5598 pairs of proteins and 1003 nodes when the cut-off value set to a comprehensive score $>0.9$ (Figure 6A). MCODE analysis showed the scores of the four modules were more than 10 (Figure 6 B-E). Analysis of 98 genes in these four modules revealed that two of them were highly correlated, and carried out submodule analysis to screen out GO, DO, and KEGG data. The two genes were S100 calcium-binding protein A8 (S100A8) and S100 calcium-binding protein A9 (S100A9).

\section{Hub genes validation}

First, we tested the relationship between S100A8 and S100A9 methylation and gene expression in the same 20 individuals in GSE88837 and GSE88940. We found that there was a negative correlation between methylation level and gene expression. The results also showed that the two correlation equation lines were statistically significant $(P<0.05)$ (Figure 7). Validation in GSE109597 showed that the expression of S100A8 and S100A9 was significantly higher in obese vs. normal subjects $(P<0.05$, Figure 8).

\section{Discussion}

Emerging evidence has shown that obesity is not only a simple nutritional excess but also a metabolic disorder, which is the precursor of many metabolic diseases (Force et al. 2018). More and more studies have confirmed that chronic inflammation is the result of the accumulation of fat cells caused by abnormal gene function (Yamaoka et al. 2014) . In the present study, the relationship between gene expression and obesity in 20 obese patients was analyzed using a gene-chip dataset. We found that the high expression of S100A8 and S100A9 was related to obesity. Also, a significant increase in S100A8 and 
S100A9 expression was observed in the validation microarray dataset of 84 samples. Whole-genome methylation analysis showed hypomethylation of the S100A8 and S100A9 promoters. Changes in methylation often lead to abnormal gene function and diseases and in this case, maybe an important cause of obesity.

Calprotectin is a heterodimer composed of S100A8 (calprotectin a, MRP8) and S100A9 (calprotectin B, MRP14) subunits, which are low molecular weight members of S100 calprotectin subfamily (Catalan et al. 2011). Previous studies have found that S100A8 and S100A9 are related to obesity, insulin resistance, and atherosclerosis (Yamaoka et al. 2013). Sekimoto et al. found that serum S100A8 / A9 complex level was related to leukocyte count, BMI, subcutaneous fat area, and visceral fat area. At the same time, compared with lean mice, obese mice had higher S100A8 mRNA expression in mature adipocyte component and obese mice had higher S100A9 expression in matrix vascular component (Sekimoto et al. 2012). Louise Lyloff et al. found that Roux-en-Y gastric bypass surgery (RYGB) significantly decreased $\mathrm{BMI}$, and circulating mRNA levels of S100A8 and S100A9 in obese patients (Lylloff et al. 2017). These findings are consistent with the present findings.

Epigenetics has become an intense topic of research in recent years. It refers to the regulation of gene expression without changing the basic structure of the gene. At present, epigenetics usually refers to histone modification, and methylation of noncoding RNA, and DNA (Wahl et al. 2017; Dick et al. 2014). Many studies have found that epigenetic mechanisms are associated with obesity. Sonne et al. found changes in methylation and expression of nine genes in epididymal adipocytes, including ehd2 and kctd15, which are known to be obesity-related genes, and a new candidate gene IRF8, which may be related to the 1 / 2 balance of immune type. Similarly, Dijk and Bell et al. also explained the relationship between DNA methylation and obesity. It is worth noting that these two studies are comprehensive in content, more stringent in inclusion criteria, extensive in research content, and very reliable in conclusions (Bell et al. 2017; van Dijk et al. 2015). Benton et al. demonstrated the relationship between DNA methylation profiles of adipose tissue and weight loss before and after gastric bypass. This study provided a strong basis for future work and additional evidence for the role of DNA methylation in adipose tissue in obesity. The findings that the promoters of both the S100A8 and S100A9 genes were hypomethylated, in addition to their significantly increased expression in obese people, confirmed the validity of our findings.

There are a few limitations to this study. First of all, our data results only come from microarrays. Although it is clear that these two hub genes play a role in the pathogenesis of obesity, in vitro and in vivo studies are required to validate the relationship between these genes and obesity.

In summary, two GEO microarrays were explored for differential methylation and gene expression as epigenetic factors of obesity. After the functional analysis, we selected two DEMGs from another microarray data set (including 84 samples) for verification. Our results showed hypomethylation and upregulation of S100A8 and S100A9 expression in obese patients. Also, correlation analysis showed that DNA methylation can regulate gene expression and lead to obesity. 


\section{Abbreviations}

VAT: Visceral adipose tissue; DMPS: Different expression positions; DMGS: Differentially methylated genes; MetS: Metabolic syndrome;T2DM: Type 2 diabetes; CVD: Cardiovascular disease; EWAS: Extensive epigenomic association studies; BMI: Body mass index;DEGS: Differential expression genes; GO: Gene ontology; KEGG: Kyoto Encyclopedia of Genes and Genomes; DO: Disease Ontology; PPI: Protein-protein interaction; MCODE: Molecular complex detection; RYGB: Roux-en-Y gastric bypass; GEO: Gene Expression Omnibus

\section{Declarations}

\section{Acknowledgments}

The authors would like to acknowledge all the participants of this study.

\section{Author's contributions}

N.-Y.C. conceived the study, participated in the design, undertook genotyping, performed the statistical analyses, and drafted the manuscript. L.M. participated in the design and analyzed the bioinformatics results. W.L. and D.-H.Z. conceived the study, and helped to draft the manuscript. L.H., J.H. and W.-X.S. collaborated to the genotyping. L.-L.L., Y.-X.L. and H.L. carried out the epidemiological survey and collected the samples. S.-L.P. and J.-H.P. supervised the whole work. All authors read and approved the final manuscript.

\section{Funding}

This research was funded by the National Natural Science Foundation of China (No:81960266) $\llbracket$ Guangxi Province Science Foundation for Youths (2018GXNSFBA281116); Open Project of Key Laboratory of Longevity and Aging-related Diseases (Guangxi Medical University), Ministry of Education (KLLAD201902)『Guangxi First-class Discipline Project for Basic Medicine Sciences (No. GXFCDP-BMS2018)『Guangxi Medical University Science Foundation for Youths (GXMUYSF201823); National Natural Science Foundation of China (NSFC: 82060072); Guangxi Self-financing Research Projects (Z20190025); Project of Liuzhou People's Hospital (LRY202007) and Guangxi Medical and Health Key Discipline Construction Project.

\section{Availability of data and materials}

The datasets used and/or analysed during the current study are available from the corresponding author on reasonable request.

\section{Ethics approval and consent to participate}

Not applicable. 


\section{Consent for publication}

All authors agree to publish this article in the journal of Molecular Medicine.

\section{Competing interests}

The authors have no potential conflicts of interest to report.

\section{Author details}

${ }^{1}$ Department of Pathophysiology, School of Preclinical Medicine, Guangxi Medical University, Nanning 530021, Guangxi, People's Republic of China. ${ }^{2}$ Department of Cardiology, Liuzhou People's Hospital, Guangxi Medical University, Liuzhou 545006, Guangxi, People's Republic of China. ${ }^{3}$ Department of Neurological Rehabilitation, Jiangbin Hospital, Nanning 530021, Guangxi, People's Republic of China.

${ }^{4}$ Department of Neurology, The Fifth Affiliated Hospital of Guangxi Medical University, Nanning 530022, Guangxi, People's Republic of China. ${ }^{5}$ The First Clinical Medical School, Guangxi Medical University, Nanning 530021, Guangxi, People's Republic of China.

\section{References}

Bader GD, Hogue CW. An automated method for finding molecular complexes in large protein interaction networks. BMC Bioinformatics 2003, 4:2.

Bell CG. The Epigenomic Analysis of Human Obesity. Obesity (Silver Spring) 2017,25:1471-1481.

Catalan V, Gomez-Ambrosi J, Rodriguez A, Ramirez B, Rotellar F, Valenti V, Silva C, Gil MJ, Fernandez-Real JM, Salvador J, Fruhbeck G. Increased levels of calprotectin in obesity are related to macrophage content: impact on inflammation and effect of weight loss. Mol Med 2011, 17:1157-1167.

Collaborators GBDO, Afshin A, Forouzanfar MH, Reitsma MB, Sur P, Estep K, Lee A, Marczak L, Mokdad $\mathrm{AH}$, Moradi-Lakeh $\mathrm{M}$, et al. Health Effects of Overweight and Obesity in 195 Countries over 25 Years. N Engl J Med 2017, 377:13-27.

Dick KJ, Nelson CP, Tsaprouni L, Sandling JK, Aissi D, Wahl S, Meduri E, Morange PE, Gagnon F, Grallert H, et al. DNA methylation and body-mass index: a genome-wide analysis. Lancet 2014, 383:1990-1998.

Force USPST, Curry SJ, Krist AH, Owens DK, Barry MJ, Caughey AB, Davidson KW, Doubeni CA, Epling JW, Jr., Grossman DC, et al. Behavioral Weight Loss Interventions to Prevent Obesity-Related Morbidity and Mortality in Adults: US Preventive Services Task Force Recommendation Statement. JAMA 2018, 320:1163-1171.

Gautier L, Cope L, Bolstad BM, Irizarry RA. affy-analysis of Affymetrix GeneChip data at the probe level. Bioinformatics 2004, 20:307-315. 
Gentleman RC, Carey VJ, Bates DM, Bolstad B, Dettling M, Dudoit S, Ellis B, Gautier L, Ge Y, Gentry J, et al. Bioconductor: open software development for computational biology and bioinformatics. Genome Biol 2004, 5:R80.

Global Burden of Metabolic Risk Factors for Chronic Diseases C, Lu Y, Hajifathalian K, Ezzati M, Woodward M, Rimm EB, Danaei G. Metabolic mediators of the effects of body-mass index, overweight, and obesity on coronary heart disease and stroke: a pooled analysis of 97 prospective cohorts with 1.8 million participants. Lancet 2014, 383:970-983.

Jensen MD, Ryan DH, Apovian CM, Ard JD, Comuzzie AG, Donato KA, Hu FB, Hubbard VS, Jakicic JM, Kushner RF, et al. 2013 AHA/ACC/TOS guideline for the management of overweight and obesity in adults: a report of the American College of Cardiology/American Heart Association Task Force on Practice Guidelines and The Obesity Society. Circulation 2014, 129:S102-138.

Lozano R, Naghavi M, Foreman K, Lim S, Shibuya K, Aboyans V, Abraham J, Adair T, Aggarwal R, Ahn SY, et al. Global and regional mortality from 235 causes of death for 20 age groups in 1990 and 2010: a systematic analysis for the Global Burden of Disease Study 2010. Lancet 2012, 380:2095-2128.

Lylloff L, Bathum L, Madsbad S, Grundtvig JLG, Nordgaard-Lassen I, Fenger M. S100A8/A9 (Calprotectin), Interleukin-6, and C-Reactive Protein in Obesity and Diabetes before and after Roux-en-Y Gastric Bypass Surgery. Obes Facts 2017, 10:386-395.

Miao L, Yin RX, Pan SL, Yang S, Yang DZ, Lin WX. Circulating miR-3659 may be a potential biomarker of dyslipidemia in patients with obesity. J Transl Med 2019, 17:25.

Miao L, Yin RX, Pan SL, Yang S, Yang DZ, Lin WX. Weighted Gene Co-Expression Network Analysis Identifies Specific Modules and Hub Genes Related to Hyperlipidemia. Cell Physiol Biochem 2018, 48:1151-1163.

Miao L, Yin RX, Zhang QH, Hu XJ, Huang F, Chen WX, Cao XL, Wu JZ. Integrated DNA methylation and gene expression analysis in the pathogenesis of coronary artery disease. Aging (Albany NY) 2019, 11:1486-1500.

Rodriguez-Rodero S, Menendez-Torre E, Fernandez-Bayon G, Morales-Sanchez P, Sanz L, Turienzo E, Gonzalez JJ, Martinez-Faedo C, Suarez-Gutierrez L, Ares J, et al. Altered intragenic DNA methylation of HOOK2 gene in adipose tissue from individuals with obesity and type 2 diabetes. PLoS One 2017, 12:e0189153.

Sayols-Baixeras S, Subirana I, Fernandez-Sanles A, Senti M, Lluis-Ganella C, Marrugat J, Elosua R. DNA methylation and obesity traits: An epigenome-wide association study. The REGICOR study. Epigenetics 2017, 12:909-916. 
Sekimoto R, Kishida K, Nakatsuji H, Nakagawa T, Funahashi T, Shimomura I. High circulating levels of S100A8/A9 complex (calprotectin) in male Japanese with abdominal adiposity and dysregulated expression of S100A8 and S100A9 in adipose tissues of obese mice. Biochem Biophys Res Commun 2012, 419:782-789.

Shannon P, Markiel A, Ozier O, Baliga NS, Wang JT, Ramage D, Amin N, Schwikowski B, Ideker Cytoscape: a software environment for integrated models of biomolecular interaction networks. Genome Res 2003, 13:2498-2504.

Smith ZD, Meissner A. DNA methylation: roles in mammalian development. Nat Rev Genet 2013, 14:204220.

Szklarczyk D, Gable AL, Lyon D, Junge A, Wyder S, Huerta-Cepas J, Simonovic M, Doncheva NT, Morris JH, Bork P, et al. STRING v11: protein-protein association networks with increased coverage, supporting functional discovery in genome-wide experimental datasets. Nucleic Acids Res 2019, 47:D607-D613.

van Dijk SJ, Molloy PL, Varinli H, Morrison JL, Muhlhausler BS, Members of Epi S. Epigenetics and human obesity. Int J Obes (Lond) 2015, 39:85-97.

Wahl S, Drong A, Lehne B, Loh M, Scott WR, Kunze S, Tsai PC, Ried JS, Zhang W, Yang Y, et al. Epigenomewide association study of body mass index, and the adverse outcomes of adiposity. Nature 2017, 541:8186.

Xu X, Su S, Barnes VA, De Miguel C, Pollock J, Ownby D, Shi H, Zhu H, Snieder H, Wang X. A genome-wide methylation study on obesity: differential variability and differential methylation. Epigenetics $2013,8: 522-$ 533.

Yamaoka M, Maeda N, Nakamura S, Mori T, Inoue K, Matsuda K, Sekimoto R, Kashine S, Nakagawa Y, Tsushima Y, et al. Gene expression levels of S100 protein family in blood cells are associated with insulin resistance and inflammation (Peripheral blood S100 mRNAs and metabolic syndrome). Biochem Biophys Res Commun 2013, 433:450-455.

Yamaoka M, Maeda N, Takayama Y, Sekimoto R, Tsushima Y, Matsuda K, Mori T, Inoue K, Nishizawa H, Tominaga $\mathrm{M}$, et al. Adipose hypothermia in obesity and its association with period homolog 1 , insulin sensitivity, and inflammation in fat. PLoS One 2014, 9:e112813.

Yu G, Wang LG, Han Y, He QY: clusterProfiler. An R package for comparing biological themes among gene clusters. OMICS 2012, 16:284-287.

\section{Figures}


Expression Value(Before normalization)

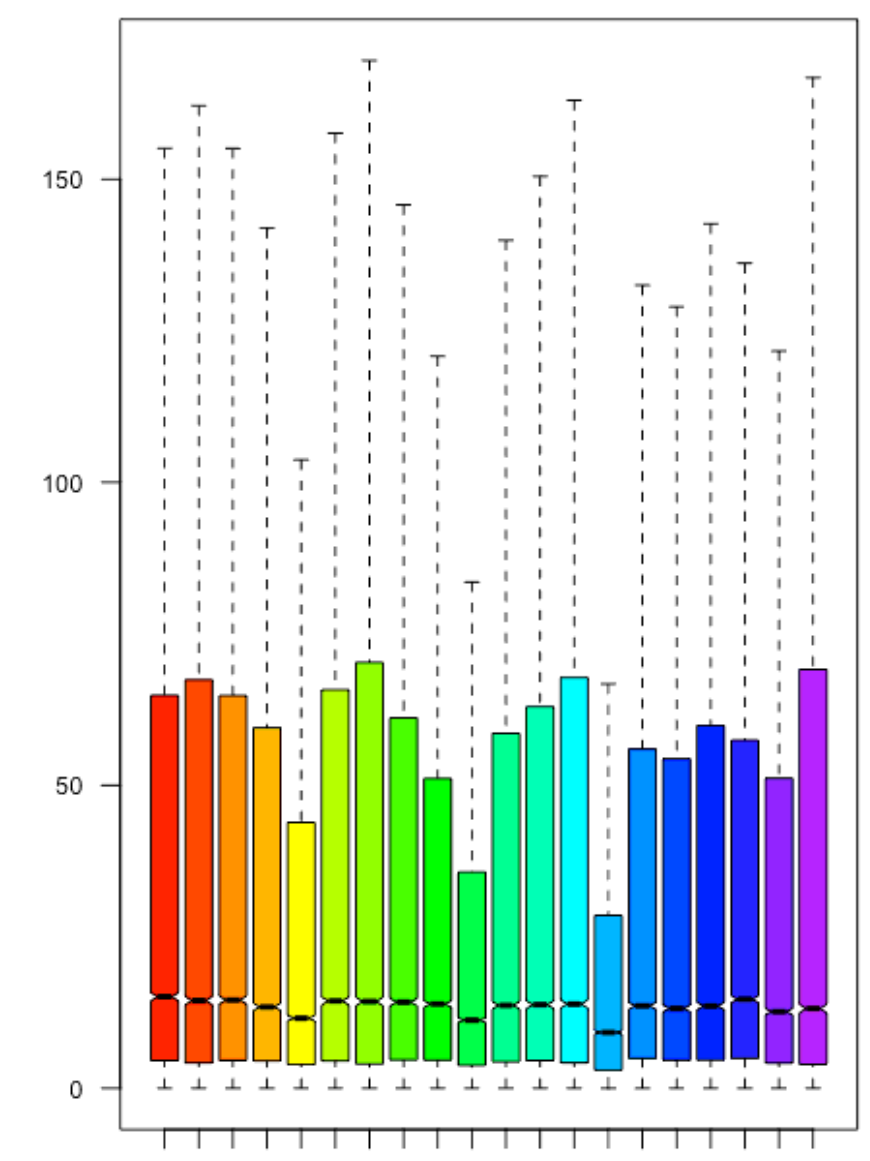

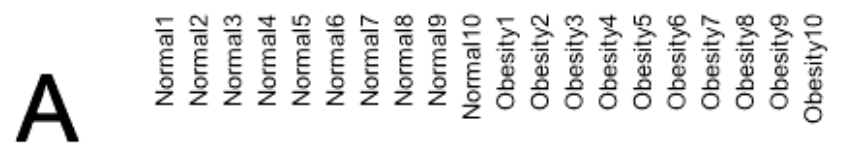

Expression Value(After normalization)

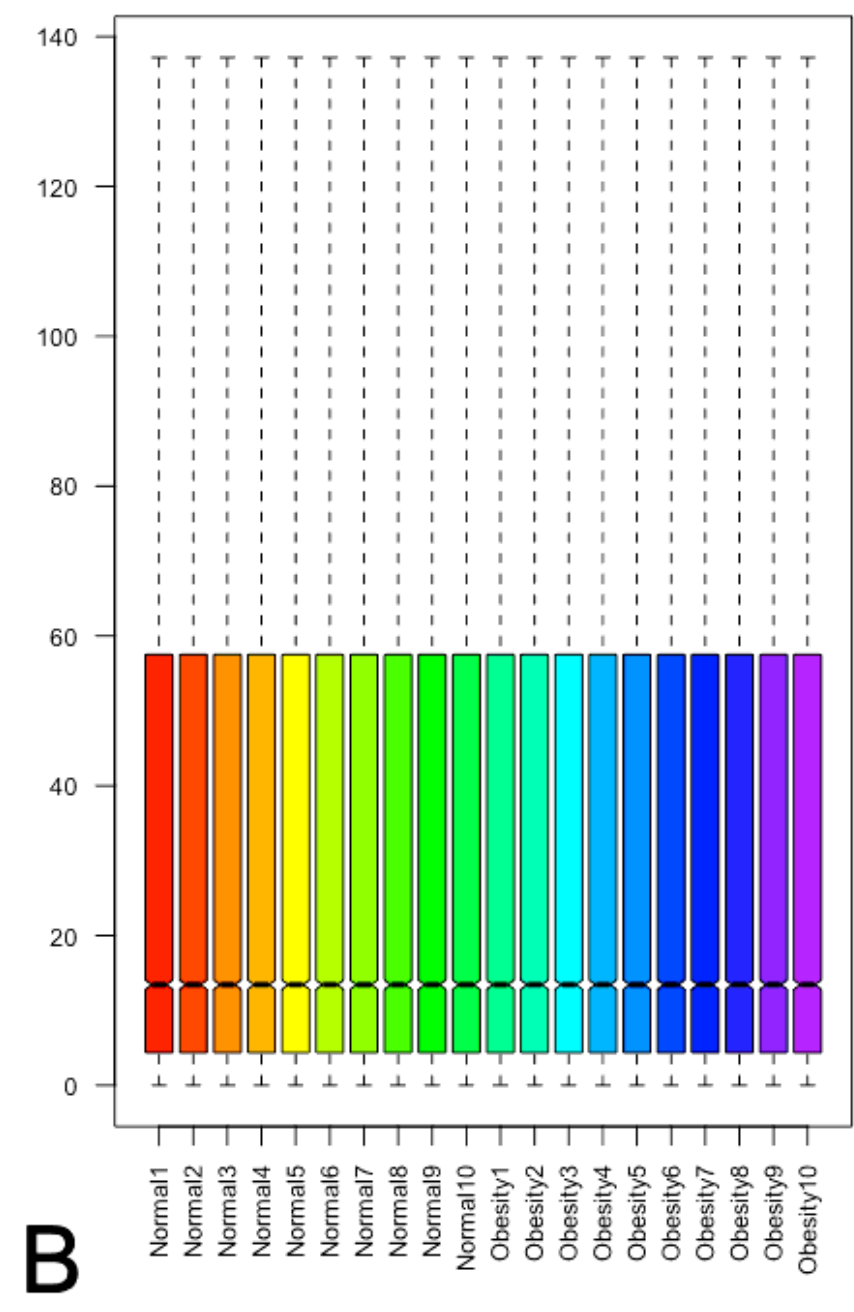

Figure 1

Normalization of all samples. (A) Before normalization; (B) After normalization. 

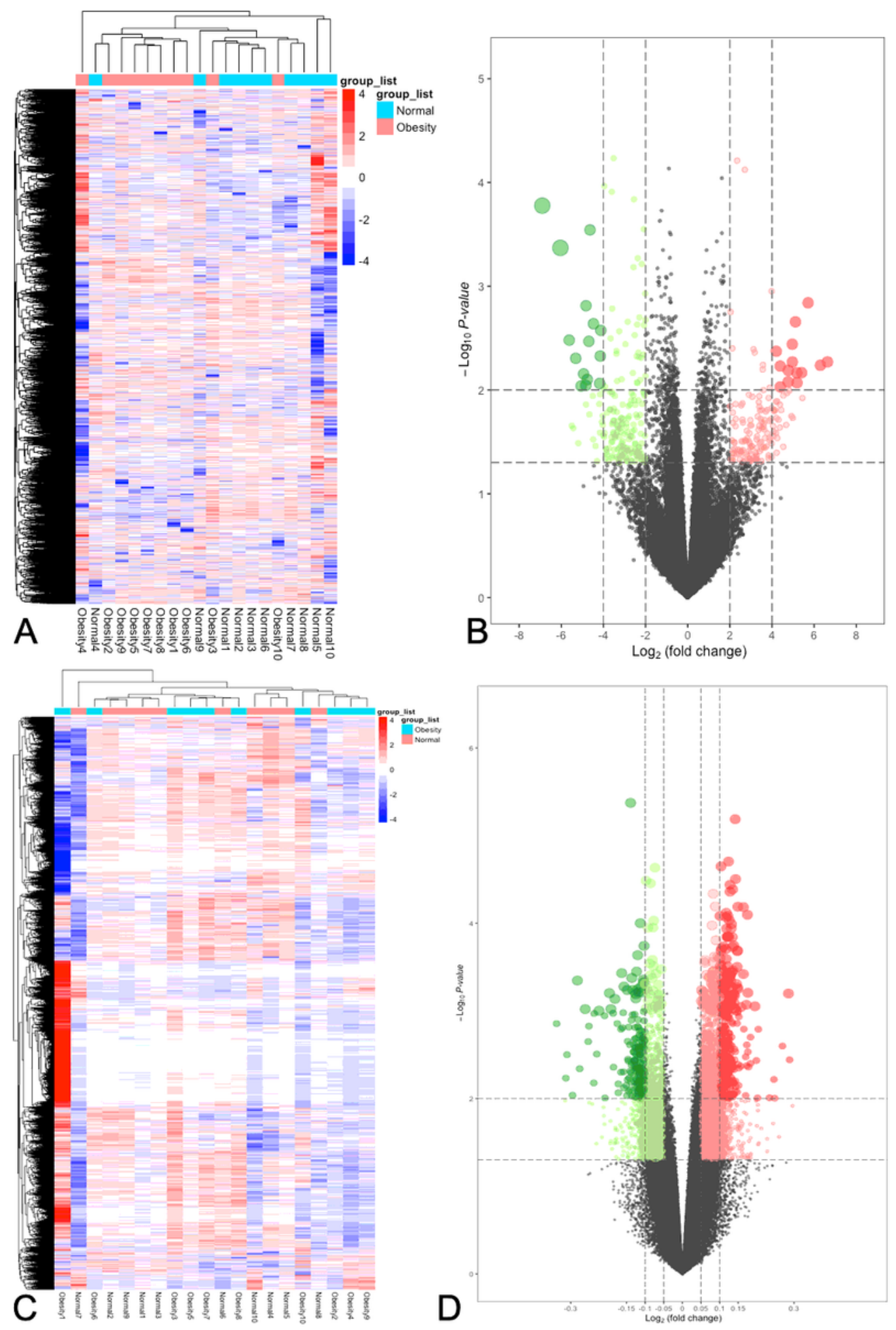

\section{Figure 2}

Heatmap and volcano plots of DEGs and DMPs. (A) Heatmap for DEGs. Obesity groups are in the red cluster, and normal samples are in the green cluster. (B) Volcano plot for DEGs. The two vertical lines are the 2 -fold change boundaries and the horizontal line is the statistical significance boundary $(P<0.05)$. Red dots show up-regulated genes, and green dots are down-regulated genes. (C) Heatmap for DMPs. Obesity groups are in the green cluster, and normals are in the blue cluster. (D) Volcano plot for DMPs. 
The vertical lines are the 0.05 -fold change boundaries and the horizontal line is the statistical significance boundary $(P<0.05)$. Up-regulated DMPs are marked with red dots, and down-regulated are marked with green dots.

\section{DEGs}

\section{DMGs}

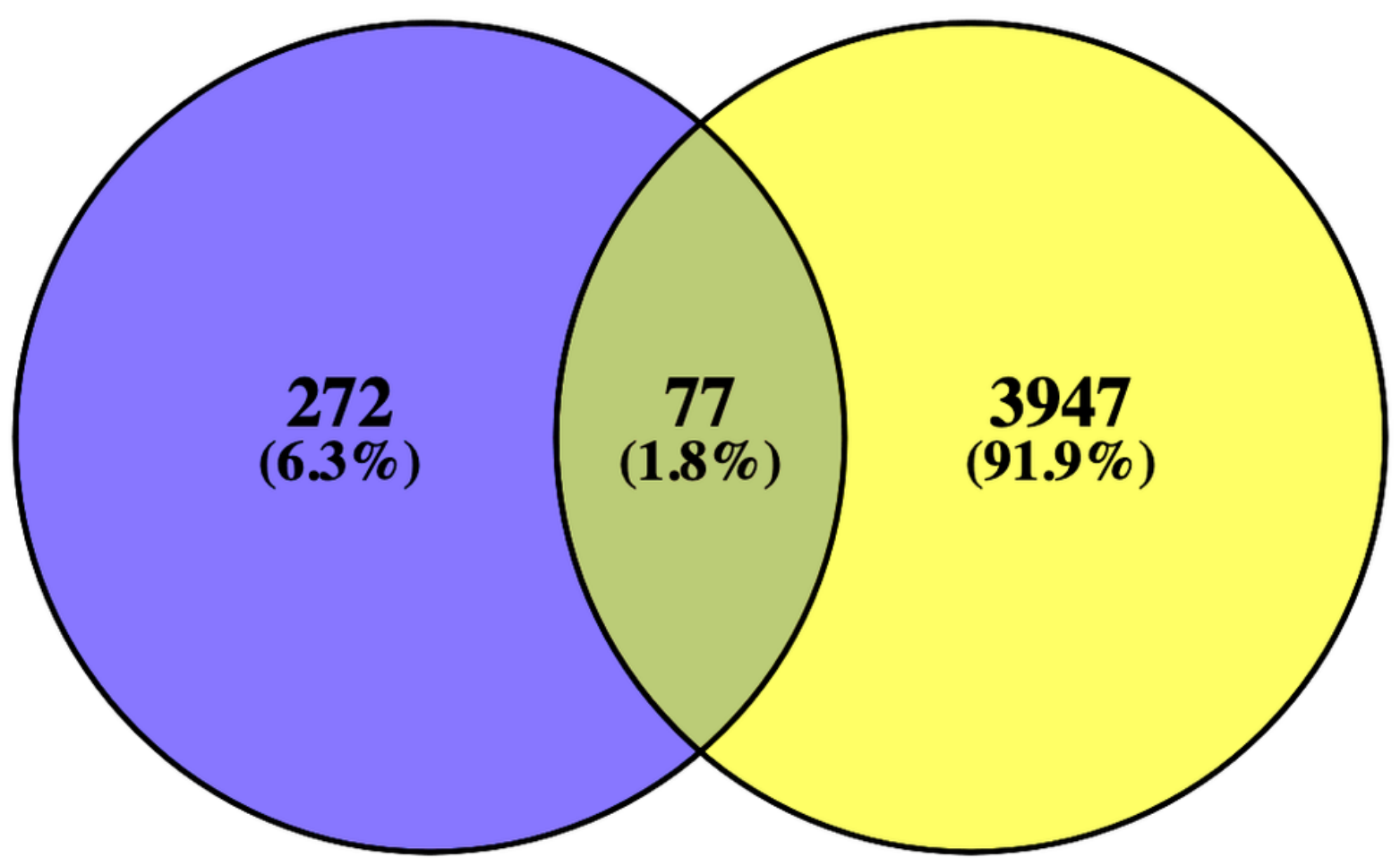

Figure 3

Venn Diagram showing the intersection of DEGs and DMGs. 


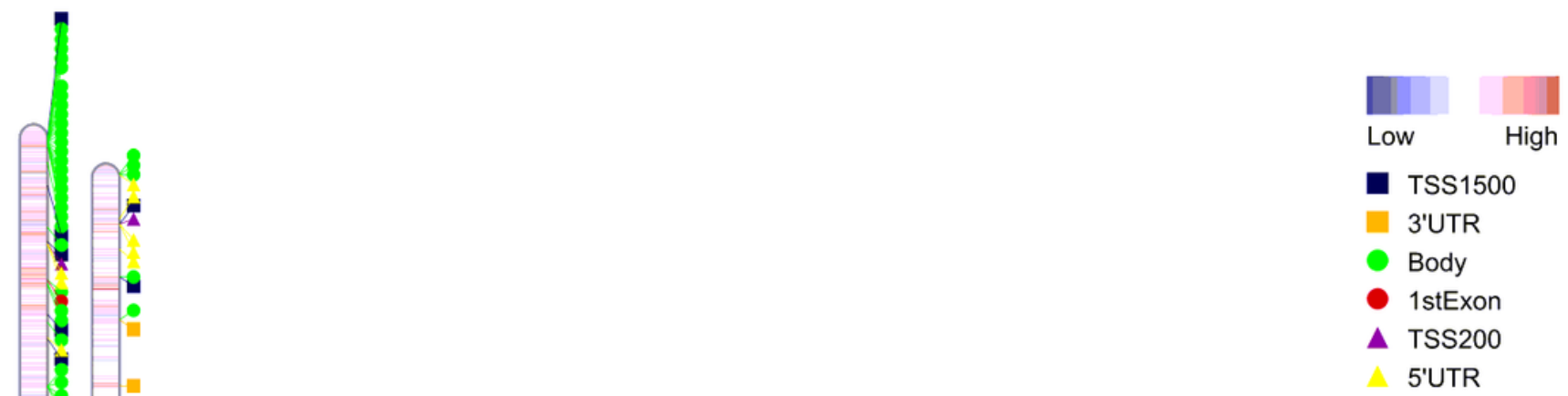

Figure 4

Chromosome distribution of differentially methylated intergenic $\mathrm{CpGs}$. Plot showing the distribution of differential intergenic $\mathrm{CpG}$ sites on 22 autosomes, and the $X$, and the $Y$ chromosomes. Red is the hypermethylated region, and blue is the hypomethylated region with logFC values of the $M$ value between obesity patients and healthy controls. 
negative regulation of transport

response to nutrient levels response to oxidative stress

response to antibiotic

response to metal ion muscle cell differentiation response to oxygen levels response to hypoxia connective tissue development protein homotetramerization

cell-substrate junction cell-substrate adherens junction focal adhesion actin cytoskeleton cell leading edge collagen-containing extracellular matrix membrane microdomain membrane region membrane raft lamellipodium

cell adhesion molecule binding actin binding

transcription factor activity, RNA polymerase II proximal promoter sequence-specific DNA binding integrin binding

A

$$
\begin{array}{r}
\text { channel inhibitor activity - } \\
\text { chemokine binding - } \\
\text { aldehyde dehydrogenase (NAD) activity - }
\end{array}
$$

$$
\text { MAPK signaling pathway }
$$

Regulation of actin cytoskeleton

Human immunodeficiency virus 1 infection-

$$
\text { Focal adhesion - }
$$

Kaposi sarcoma-associated herpesvirus infection-

Fluid shear stress and atherosclerosisOsteoclast differentiation -

C-type lectin receptor signaling pathwayTNF signaling pathway-

IL-17 signaling pathway-

AGE-RAGE signaling pathway in diabetic complications -

Fc gamma R-mediated phagocytosis -

Biosynthesis of amino acids -

Chemical carcinogenesis -

VEGF signaling pathway -

Glycolysis / Gluconeogenesis -

Drug metabolism - cytochrome P450-

Arginine and proline metabolism -

Alanine, aspartate and glutamate metabolism -

Histidine metabolism -

Phenylalanine metabolism -

Fatty acid biosynthesis -

B

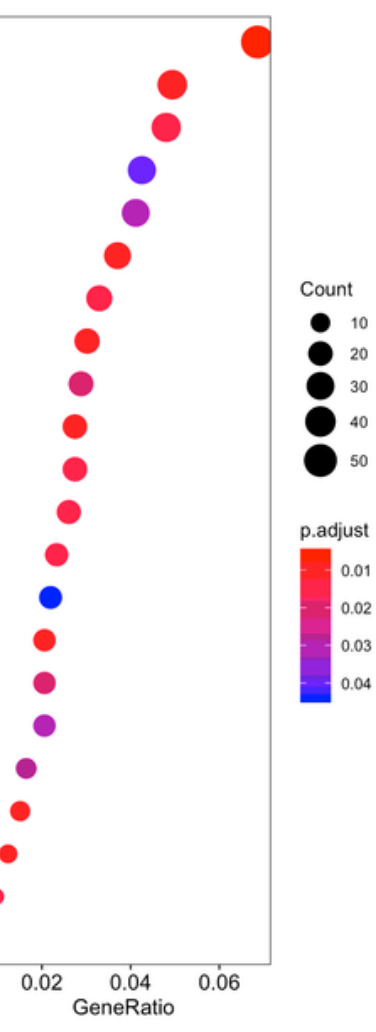

0.01

0.02

\section{GeneRatio}

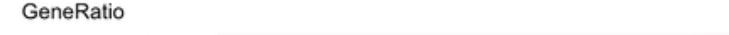

\section{Figure 5}

Functional enrichment of DEGs. The $x$-axis shows the ratio number of genes and the $y$-axis shows the pathway terms. The -log10 (P-value) of each term is colored according to the legend. (A) Gene Ontology; (B) Kyoto Encyclopedia of Genes and Genomes (KEGG) pathway analysis; (C) Disease Ontology 


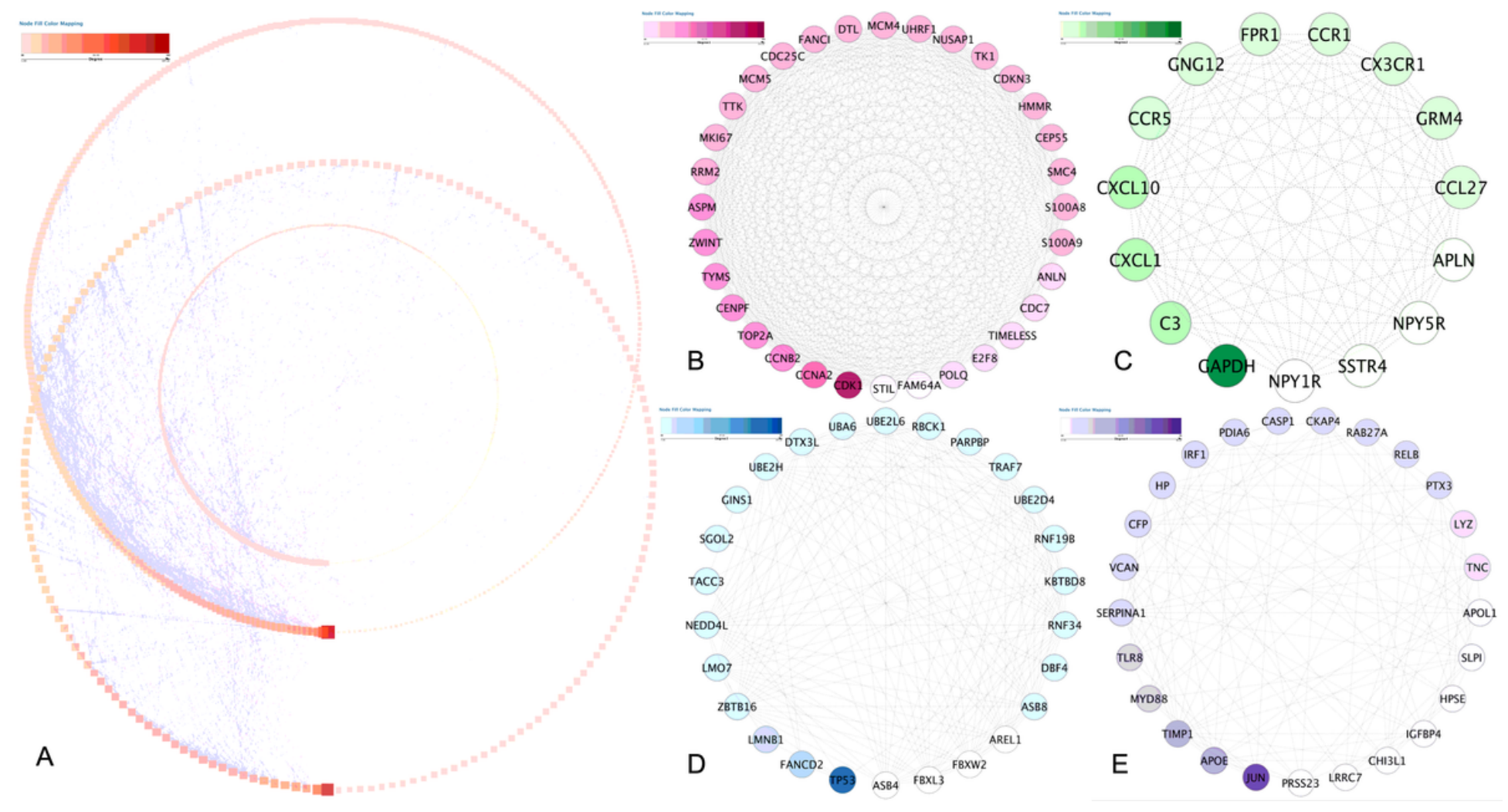

Figure 6

Protein-protein interaction network analysis. (A) Protein-protein interaction network of the module genes. Edge stands for the interaction between two genes. A degree was used for describing the importance of protein nodes in the network, darkness red shows a high degree and light presents a low degree. (B - E) The significant modules identified from the protein-protein interaction network using the molecular complex detection method with a score of $>$ 8.0. MCODEB score $=22.166$, MCODEc score $=17.442$, MCODED score $=9.278$ and MCODEE score $=8.963$.

S100A8

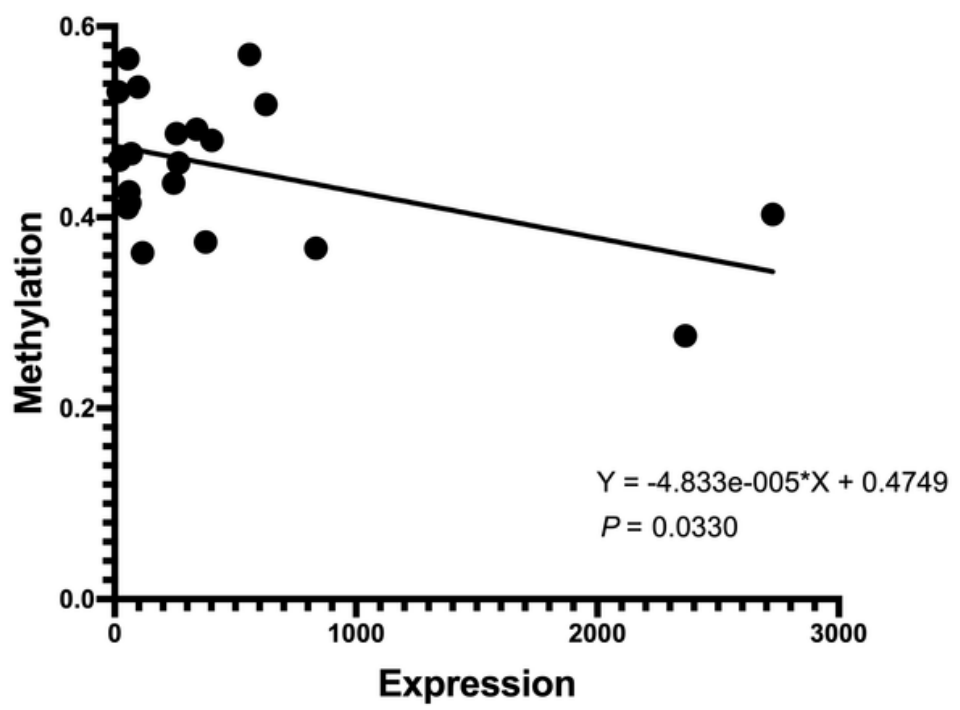

S100A9

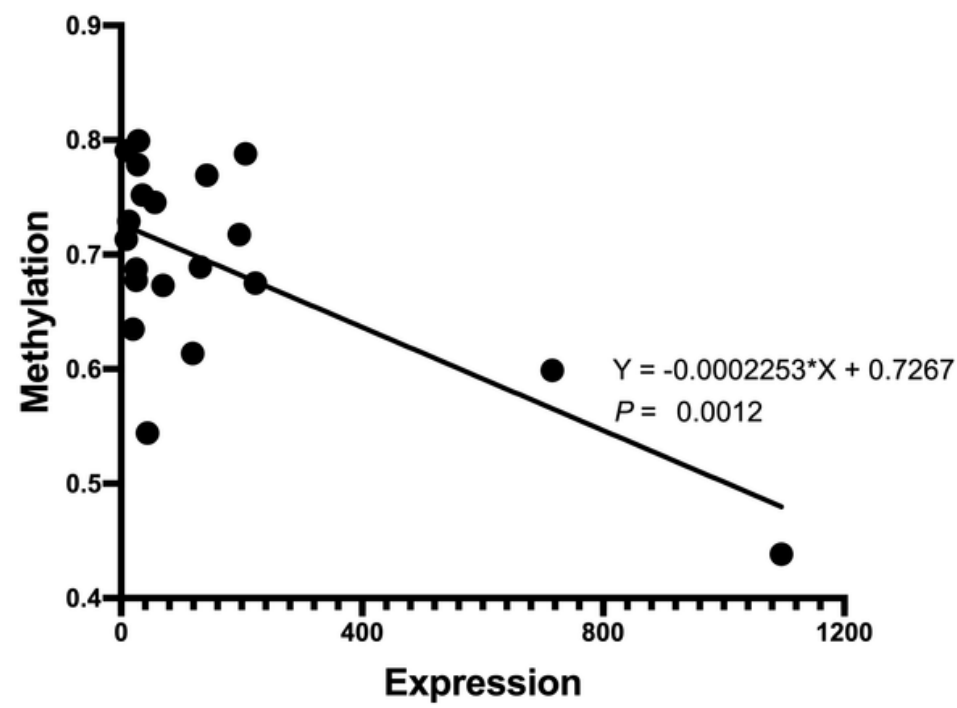

Figure 7 
Correlation analysis of DNA methylation and mRNA expression.

S100A8

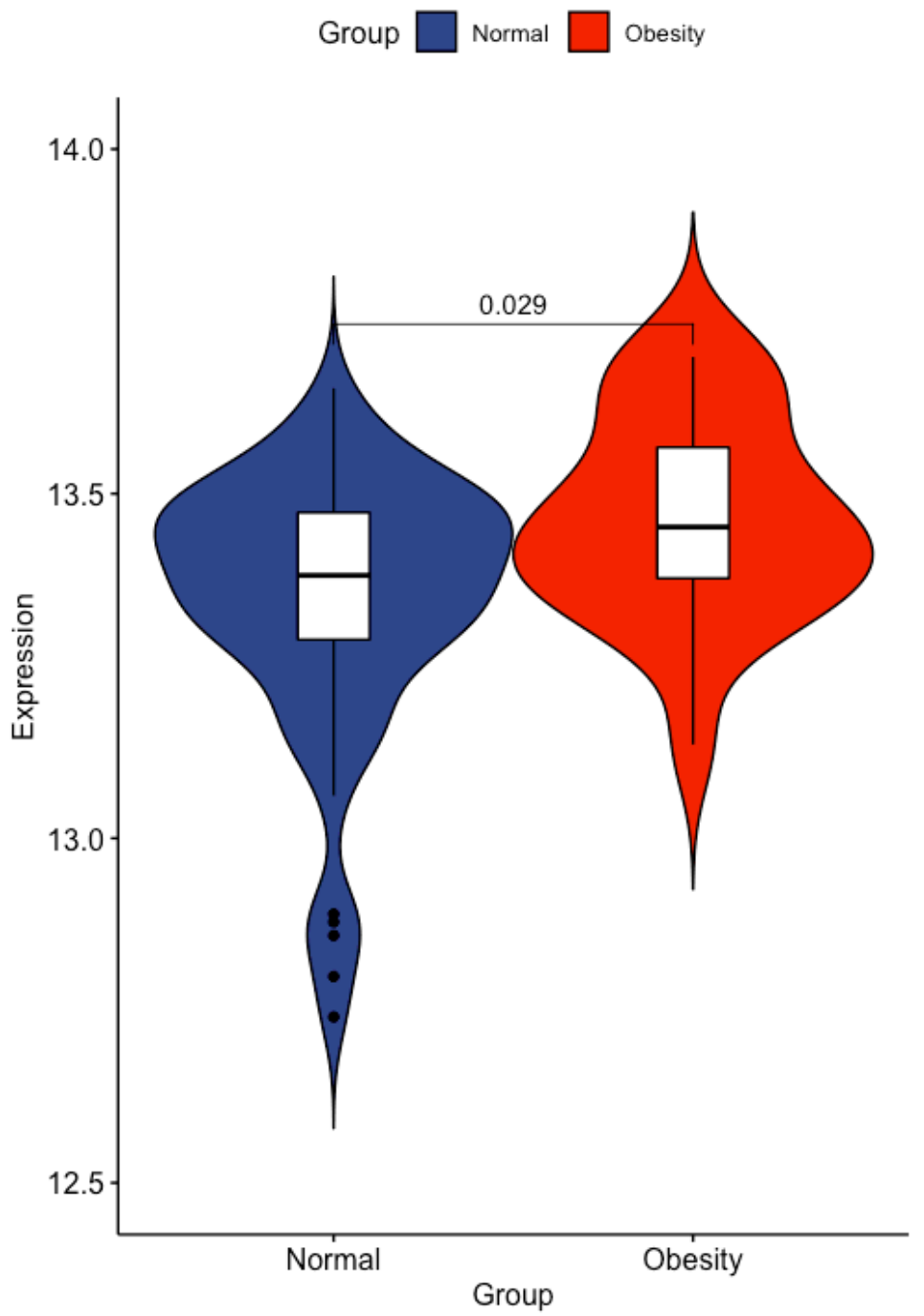

S100A9

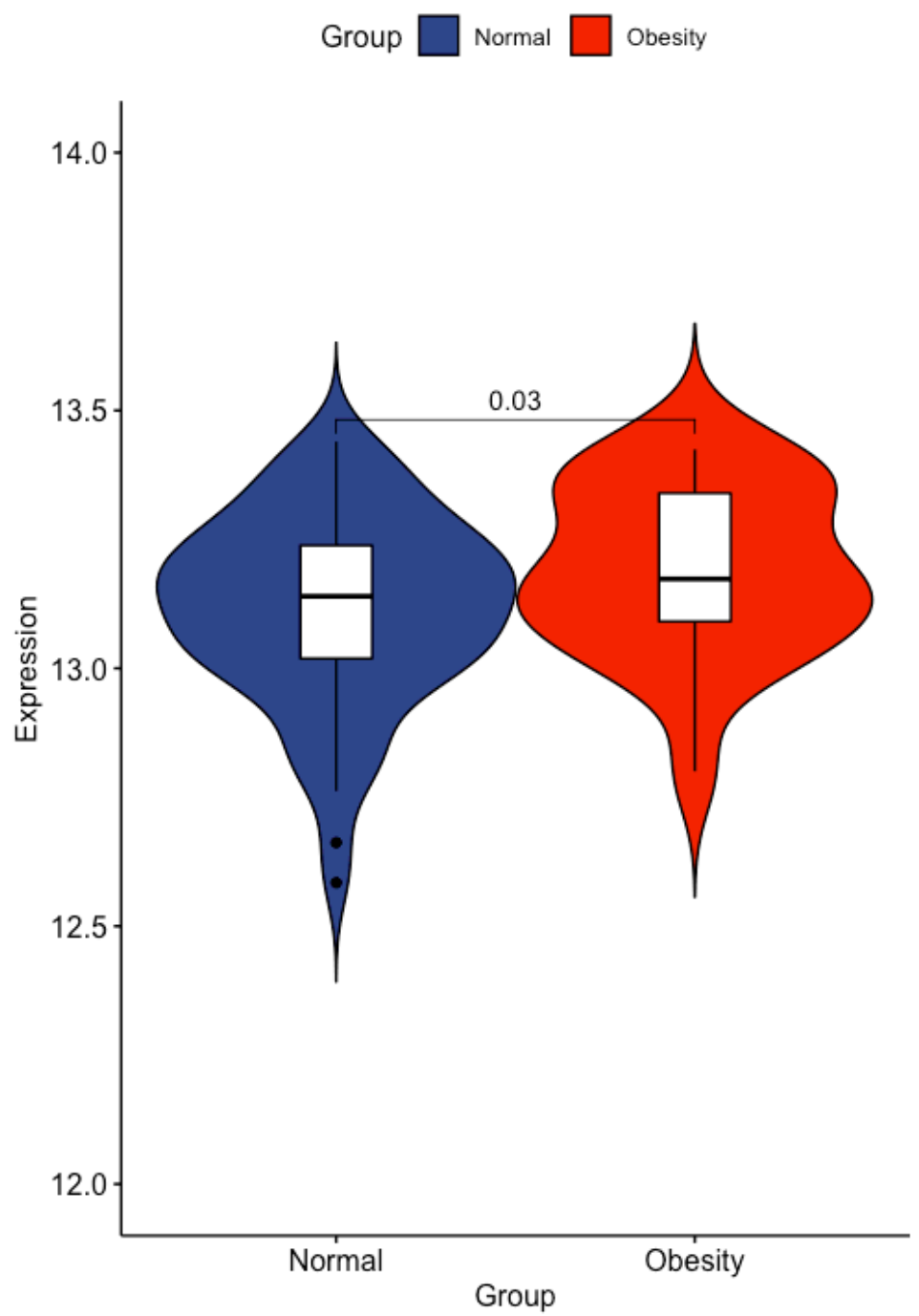

Figure 8

Verification of mRNA expression between obese and healthy samples in GSE109597.

\section{Supplementary Files}

This is a list of supplementary files associated with this preprint. Click to download.

- SupplementaryTable3.csv

- SupplementaryTable2.csv

- SupplementaryTable1.csv 